\title{
Viral Particle Unit
}

National Cancer Institute

\section{Source}

National Cancer Institute. Viral Particle Unit. NCI Thesaurus. Code C67350.

A unit for virus amount measurement that represents the total number of viral particles

(live and dead combined). 